\title{
Exploring the influence of pre-service mathematics teachers' professed beliefs on their practices in the Sri Lankan context
}

\author{
Gayanthi Malika Wadanambi ${ }^{1}$ and Frederick K. S. Leung ${ }^{2}$ \\ ${ }^{1}$ Nilwala National College of Education, Sri Lanka \\ ${ }^{2}$ Faculty of Education, The University of Hong Kong, Hong Kong
}

Research on impact of teacher beliefs on their practices has been recognized as one of the important aspects in the discipline of mathematics education. This study reports the results of a case study that gives an insight about the influence of professed beliefs of pre-service secondary mathematics teachers on their instructional practices in the Sri Lankan context. The pre-service teachers' professed beliefs were examined by using a questionnaire of six-point Likert scale items. Data on instructional practices were collected through classroom teaching observations and follow-up post-lesson interviews. Qualitative analysis of the audio-taped classroom teaching observation transcripts was performed, using a list of sensitizing concepts that reflected flexible and rigid beliefs aspects. The results reveal that professed beliefs encouraged them to adopt flexible practices, but to differing extents due to the influence of social expectations and contextual demands embedded within this educational context

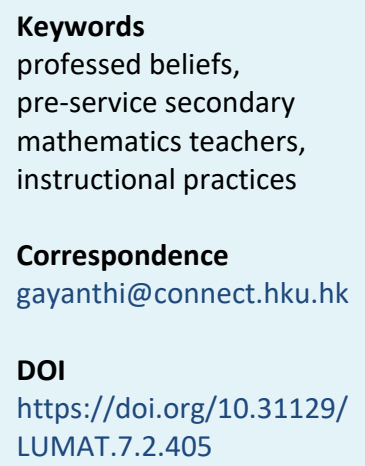

\section{Background}

Several scholars have emphasized the significant role played by teachers' beliefs in shaping teachers' instructional practices (Leung, Graf, \& Lopez-Real, 2006; Thompson, 1992; Pepin \& Roesken-Winter, 2015). Leder, Pehkonen, and Törner (2002) discussed the complexity of beliefs, noting that they have been studied in different disciplines and from a variety of perspectives. Furinghetti and Pehkonen (2002), in their examination of how researchers from the 1980s and the $1990 \mathrm{~s}$ characterized the concept of belief and which dimensions they used to do so, found that most focused on the static aspects of beliefs (e.g., how beliefs are constructed, what constitute beliefs etc.) and little on their more dynamic aspects (e.g., how beliefs function).

Mathematics teachers from different cultures have their own beliefs, which they translate into unique teaching approaches (An, Kulm, Wu, Ma, \& Wang, 2006). In the literature, some studies (Swars, Hart, Smith, Smith, \& Tollar 2007; Hart, 2002) paid attention to the impact of teacher preparation program on changing beliefs of the student teachers. Hart (2002), for example, showed that successfully completing a certification program in teaching changed pre-service teachers' beliefs. Van Zoest, 
Jones, \& Thornton (1994), in their study examining the beliefs and practices of preservice primary mathematics teachers engaged in a mentorship program, found that the primary pre-service teachers' professed beliefs had been influenced by the socioconstructivist approach to mathematics instruction promoted by the mentorship program.

Other studies on the relationship between beliefs and practice reported both consistencies and inconsistencies. Examining recent studies that addressed the dialectic relationship between teacher beliefs and practice, Goldin et al. (2016) pointed out that the discrepancy between beliefs and practices is still an open issue. In another former study, Cooney (1985) examined the professed beliefs of one preservice mathematics teacher (Fred) and found his professed beliefs to align with a problem-solving approach to teaching mathematics; however, when Fred attempted to pose recreational problems, on certain occasions his practices did not match his professed beliefs. Cooney noted that, although Fred attempted to conduct his teaching in accordance with his professed beliefs, he was not always able to do so, as actual classroom teaching practices were affected by other factors, such as students' not being used to learning mathematics by using problem-solving heuristics in their learning context.

Raymond (1997) reported another example of teachers' beliefs and practices being inconsistent due to extraneous factors. He examined six teachers to determine the influence of beliefs on practice, and found that even a single element in the immediate classroom situation could influence teachers' mathematics teaching practice more than their mathematics beliefs; the topic at hand, time constraints and prior school experiences, such as teachers' preparation programs and prior experiences as students, were all factors that could change teachers' practices.

Moreover, the impact of mathematics teachers' beliefs about the nature of mathematics and of learning and teaching mathematics on classroom teaching practice has been suggested by previous research findings and theoretical papers (Ernest, 1989; Pajares, 1992; Thompson, 1992). Some, like Thompson (1992), reported both consistencies and inconsistencies between mathematics teachers professed beliefs and actual practices. However, systematic research related to mathematics teachers' beliefs and their practices is rare in the Sri Lankan context, and there is a void in the literature on the relation between teachers' beliefs and their practices within the sociocultural context of Sri Lanka. As such, the present study focuses on Sri Lankan pre-service teachers' professed beliefs about the nature 
of mathematics and of teaching and learning mathematics, and the impact of these beliefs on their actual teaching practices.

\section{Theoretical Underpinning}

In the literature different arguments have been made regarding the concept of teacher beliefs, and there is no clear consensus on their definition. The nature of different understanding of beliefs has been reported in the literature. Ernest (1989) suggested that knowledge is the cognitive outcome of thought and belief is the affective outcome, but beliefs also possess a slight but significant cognitive component. A similar interpretation was given in Pajares (1992) by going through a thorough review of the literature to distinguish between knowledge and beliefs which suggests that knowledge of a domain differs from feelings about a domain.

McLeod (1992) differentiated between beliefs, attitudes, and emotions, stating that beliefs are largely cognitive in nature relative to attitudes and emotions. As such, it can be noticed that although the term beliefs largely reflect the affective domain, it cannot be totally detached from the cognitive domain. Values are another crucial and emerging construct in mathematics education which has not yet been addressed largely (Seah, Andersson, Bishop, \& Clarkson, 2016). The term 'values' refers to what one considers as important such as a certain belief being considered as something of importance and significance.

The current study focuses on the theoretical construct of professed beliefs of preservice teachers. In this study, professed beliefs refer to what teachers express as their conceptions of the nature of a discipline (mathematics) and about a phenomenon (learning and teaching mathematics). This report focuses on professed beliefs about the nature of mathematics, and learning and teaching mathematics (Ernest, 1989). Teachers' beliefs regarding the nature of mathematics are referred to as teachers' conceptions of the nature of mathematics. Ernest (2004) paid much attention in elaborating on the absolutist-fallibilist distinction, assuming that the choice between the two would be the most influential epistemological factor on mathematics teaching. Therefore, it is important to explore mathematics teachers' beliefs about epistemology of mathematics and mathematics education; and their impact on teaching.

The term 'instructional practice' in this study indicates actual classroom teaching that facilitates students to acquire content by creating a conversation providing 
reasons, justifications, explanations, and conclusions. Referring to the abovementioned theories, this study focuses on the instructional practices of pre-service teachers and the influence of teachers' professed beliefs and any other factors on those practices.

\section{Method}

The research question that guided this study is: What is the relationship between Sri Lanka's pre-service mathematics teachers' professed beliefs and their instructional practices? This is a part of a larger study that employed a survey and a case study. In the larger study, we examined teacher knowledge and their professed beliefs by employing a survey over a cohort $(n=126)$ of the third-year, Sinhala-medium, preservice secondary mathematics teachers enrolled in a three-year pre-service teacher education course at National Colleges of Education in Sri Lanka. Afterwards we conducted a case study, by selecting cases from the survey study, to explore the impact of teacher knowledge and beliefs on their instructional practices. We presented the results on teacher beliefs in an oral communication session at the $13^{\text {th }}$ International Congress on Mathematics Education (Wadanambi, \& Leung, 2016). However, we present a brief introduction about the beliefs questionnaire and the procedure of selecting cases below. The beliefs questionnaire consisted of four subscales adopted from Teacher Education and Development Study in Mathematics (TEDS-M) project's framework (Tatto, Schwille, Senk, Ingvarson, Peck, \& Rowley, 2008) related to beliefs about the nature and learning of mathematics. We used two subscales - 'Mathematics as a set of Rules and Procedures' (Rules and Procedures) and 'Mathematics as a Process of Enquiry' (Process of Enquiry) to portray the beliefs about the nature of mathematics, and the sub-scales 'Learning Mathematics through Following Teacher Direction' (Teacher Direction) and 'Learning Mathematics through Active Involvement' (Active Involvement) to characterize the beliefs about learning and teaching mathematics. Statements in the Rules and Procedures scale and that of the Teacher Direction scale reflect rigid views while statements in the Process of Enquiry and Active Involvement scales reflect flexible views about mathematics as well as mathematics education as a discipline. We asked the participants to respond to each statement given in the beliefs scales by choosing among six-point Likert scale response alternatives from "strongly disagree" to "strongly agree". The study determined the overall degree to which each belief category was endorsed based on participants responses to each category. We 
considered the responses "Agree" and "Strongly agree" to be endorsements of the respective statements. We considered that the participant has endorsed the particular belief if his or her mean rating for a given scale was equal to or greater than 5. We selected the two cases described in this paper from the category those who professed to hold flexible views.

Flexible views meant those held by pre-service teachers who strongly endorsed mathematics as a process of enquiry and learning mathematics through active involvement. Rigid view holders meant those who endorsed mathematics as a set of rules and procedures and learning mathematics through teacher direction. However, there were no participants to represent rigid view category since none of the participants supported learning mathematics by teacher direction (see Table 2). Moreover, we defined the average of Process of Enquiry and Active Involvement scales as a measure to indicate the degree of flexibility of the participants' views (beliefs), and to use that as a criterion for selecting even more flexible view holders among the participants.

We collected data on actual instructional practice during the internship year of the two pre-service teachers. Although secondary mathematics pre-service teachers are trained to teach mathematics to Grade 6-11 classes, during the internship training period they are more likely to be assigned to teach in Grade 6-9 classes. Therefore, we focused the topic of Algebraic Expressions which is generally taught in the second term of the year at the Grade 8 level, in this study. Depending on their teaching approaches, each teacher needed three or four 40-minute lessons to complete the topic. Throughout the lesson, we audio-taped each of the lesson and took field notes, particularly concerning situations that could not be audio-recorded (e.g., explanations written, or images drawn on blackboards, non-verbal studentteacher interactions, student responses to visuals used by the teacher, etc.). To clarify observed teaching and learning incidents, we conducted post-lesson interviews after each lesson. We audio-recorded the interviews and transcribed them for use in the data analysis process. 


\section{Data Analysis}

When analyzing the beliefs questionnaire responses, we counted a participant to have endorsed a particular belief, if their mean rating for a given scale was equal to or greater than five. To spot the general pattern of the prospective teachers' professed beliefs, we also calculated the overall mean ratings for each beliefs scale, by averaging the mean ratings of all participants under each scale.

To analyze the classroom observation transcripts, we identified a list of sensitizing concepts including specific tasks, activities, or behaviors that reflected aspects of beliefs. We scrutinized the lists of sensitizing concepts used in previous studies (An, Kulm, \& Wu, 2004; Leung, 1995) when analyzing classroom teaching observation data, particularly those that reflected aspects of teacher beliefs about mathematics and mathematics teaching and learning. Drawing on the key features mentioned in various previous studies, we created a theory-driven list of sensitizing concepts corresponding to different views of mathematics and mathematics teaching and learning. Then we modified the list to match the available classroom teaching observation data from the current study (see Table 1). Based on the list of sensitizing concepts the researcher coded the classroom observation transcripts; and the researcher invited a university academic from a Sri Lankan university department of mathematics to code a part of the data to verify and increase the reliability of the coding. The inter-rater coded three lessons out of seven transcripts. Whenever inconsistencies in the coding arose, the researcher and the inter-rater resolved them through keeping discussions between them. After coding the transcripts, we reported the frequencies for each type of incidents observed in the teaching/learning process.

Table 1. Sensitizing concepts that reflect Flexible View and Rigid View aspects.

\begin{tabular}{llll}
\hline $\begin{array}{l}\text { Flexible } \\
\text { View }\end{array}$ & 31 & Sensitizing concepts & Alternative methods \\
32 & $\begin{array}{l}\text { Pescription } \\
\text { explanations }\end{array}$ & $\begin{array}{l}\text { Teacher encourages students to perform alternative methods to figuring out } \\
\text { the same problem or invent their own methods. }\end{array}$ \\
& $\begin{array}{l}\text { Teacher highlights the mathematical principles in explanations. Teacher not } \\
\text { only states the facts but rather, focuses the issues such as why it works, how } \\
\text { do we know, would it ever be true. }\end{array}$ \\
& $\begin{array}{l}\text { Investigation or } \\
\text { exploration tasks }\end{array}$ & $\begin{array}{l}\text { Teacher engages students in investigation or exploration-based activities in a } \\
\text { small group setting or individualized setting. }\end{array}$ \\
\hline
\end{tabular}




$\begin{array}{llll}\begin{array}{l}\text { Rigid } \\ \text { View }\end{array} & 41 & \begin{array}{l}\text { Fixed steps in solving } \\ \text { problems }\end{array} & \begin{array}{l}\text { Teacher repeats or reminds students about the fixed order of steps to } \\ \text { execute in solving problems, or teacher emphasizes fixed order of steps } \\ \text { rather than letting students to attempt their own steps. }\end{array} \\ 42 & \begin{array}{l}\text { Algorithmic or procedure- } \\ \text { oriented explanations }\end{array} & \begin{array}{l}\text { Teacher highlights/focuses the steps in an algorithm or procedure without } \\ \text { mentioning the principle. }\end{array} \\ 43 & \begin{array}{l}\text { Drilling and practice- } \\ \text { oriented tasks }\end{array} & \begin{array}{l}\text { Teacher wants students to practice a number of similar exercises rather than } \\ \text { understanding the procedure. }\end{array} \\ 44 \begin{array}{l}\text { Memorizing facts and } \\ \text { procedures }\end{array} & \text { Teacher wants students to memorize the terminologies, facts or procedures. }\end{array}$

\section{Results}

\subsection{Results of beliefs questionnaire}

A summary of the participants' endorsements on each of the beliefs scales is displayed in Table 2

Table 2. Participants' endorsement and mean rating of the degree of agreement on each scale.

\begin{tabular}{llll}
\hline Scale & No. of participants endorsed & \% of participants endorsed & Mean rating \\
\hline Rules and Procedures & 29 & $23.01 \%$ & 4.48 \\
Process of Enquiry & 91 & $72.22 \%$ & 5.15 \\
Teacher Direction & 0 & $0 \%$ & 2.81 \\
Active Involvement & 91 & $72.22 \%$ & 5.15 \\
\hline
\end{tabular}

The above results show that flexible views of both the nature of mathematics and of teaching and learning mathematics were rated more highly by participants than were rigid views. The two cases described in this paper were drawn from among those whose reported beliefs index was greater than five, indicating they held more flexible views (see Table 3). They are known as Sudam and Jayani in this paper.

Table 3. Beliefs indicators of the case study teachers.

\begin{tabular}{llll}
\hline Name & Process of Enquiry & Active Involvement & (PE+AI)/2 \\
\hline Sudam & 5.17 & 5.17 & 5.17 \\
Jayani & 6.00 & 5.83 & 5.92 \\
\hline
\end{tabular}




\subsection{Results of instructional practices}

\subsubsection{Context of the instructional Practices}

In general, chalk and blackboard were the major teaching/learning resources available to and used by the teachers in this research context. The two schools in which the instructional practice observation took place were mixed schools, with both male and female students learning in the same school. Inside the classrooms, male students sat on one side and females on the other. Each student had a desk and chair, and there were usually about 40 students in a classroom. There were no technological resources, such as computers or overhead projectors in the classrooms.

The observed lessons taught by the two participants both focused on constructing algebraic expressions, substituting values into algebraic expressions, constructing algebraic expressions containing brackets, and obtaining a method to remove brackets from an algebraic expression. Both schools were similar in most major respects. Both were mixed schools in which each class consisted of about 40 students, comprised of nearly equal numbers of boys and girls. In academic terms, the schools were neither higher- nor lower- level schools; rather, both were midlevel schools. Both schools were located in urban areas and, generally speaking, their students' achievement levels and their families' socio-economic statuses were also similar.

\subsubsection{Results of observations of classroom teaching}

Table 4 reports the frequencies of the teaching instances coded under flexible view (FV) and rigid view (RV) in relation to the practices of the case study teachers Sudam and Jayani.

Table 4. Frequencies of incidents related to Flexible View and Rigid View aspects.

\begin{tabular}{llll}
\hline & Sensitizing concepts & Sudam & Jayani \\
\hline \multirow{4}{*}{ Flexible View } & 31 Alternative methods & 1 & 3 \\
& 32 Principle-oriented explanations & 4 & 3 \\
& 33 Investigation or exploration tasks & - & - \\
& Total number of flexible view incidents & $\mathbf{5}$ & $\mathbf{6}$ \\
\hline \multirow{5}{*}{ Rigid View } & 41 Fixed steps in solving problems & 1 & \\
& 42 Algorithmic or procedure-oriented explanations & 2 & 1 \\
& 43 Drilling and Practice oriented tasks & - & - \\
& 44 Memorizing facts and procedures & 3 & - \\
\hline
\end{tabular}


A classroom incident that reflects the sensitizing concept Alternative methods is described below to make it sensible for the reader as an example.

\subsubsection{Incident from Jayani's lesson (alternative methods):}

Context: The objective of the lesson was to learn how to construct algebraic expressions containing brackets. The teacher drew a floor plan of a building with three rooms (Figure 1), of lengths p, q, and r, on the blackboard and asked students to construct an algebraic expression to represent the building's perimeter.

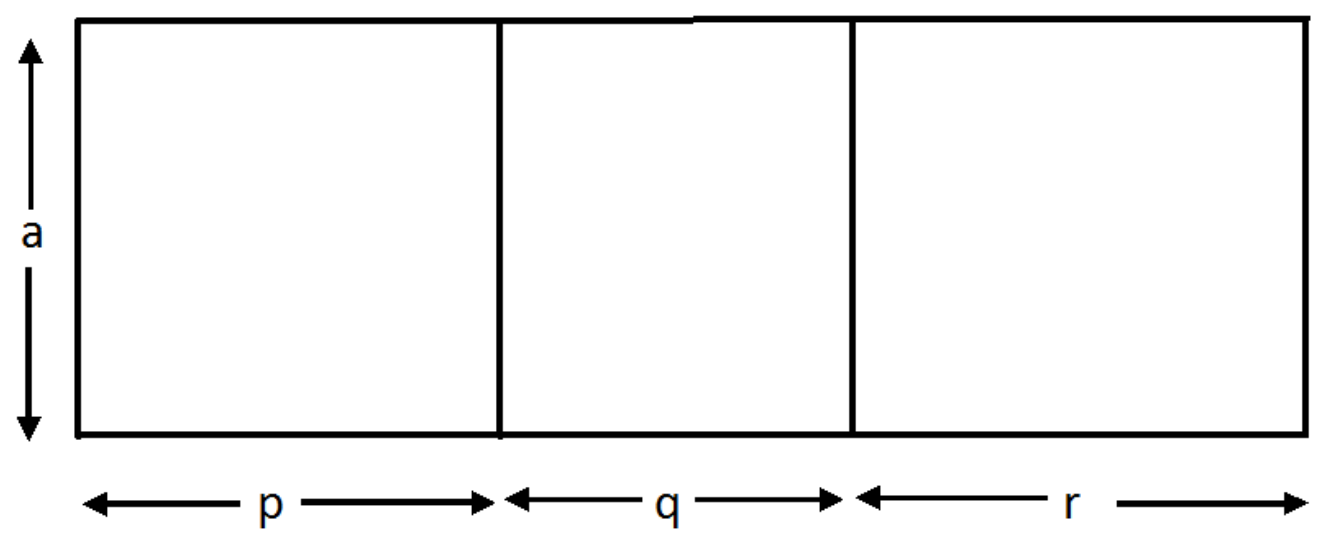

Figure 1. Floor plan of a building used as the context for algebra in Jayani's lesson (reproduced).

The teacher said, "Your friends have used two methods. Let's see what they are.", and then started a whole-class discussion about two approaches the students had used to formulate the expression and the appropriateness of each method.

Teacher: "If this side can be expressed as $p+q+r$, this side also can be expressed as $\mathrm{p}+\mathrm{q}+\mathrm{r}$ [pointing to the longer sides of the rectangle], alright? Can it be written as [the teacher wrote $(p+q+r)+(p+q+r)$ on the blackboard] or can it be .... [ writing $2(p+q+r)$ on the blackboard]? Are these two things or one thing?"

Students: "One thing."

Teacher: "Yes, equal or not?"

Students: "Equal."

Teacher: "Those who wrote this [pointing to $(p+q+r)+(p+q+r)$ ] and also those who wrote this [pointing to $2(p+q+r)$ ] are correct. If so, tell me what the width is. a unit? What is the width of whole building? $2 a .$. then this 
is also added to this. Now, can it be simplified further? ...can, I now write the same thing without brackets? Now... see like terms are added. Two $p$ s..."

Students: "Two $p$...two q...two $r$ "

Teacher: "That means two of the long sides. Now, $2 a$ is added to this (Figure 2). Can this be simplified further?"

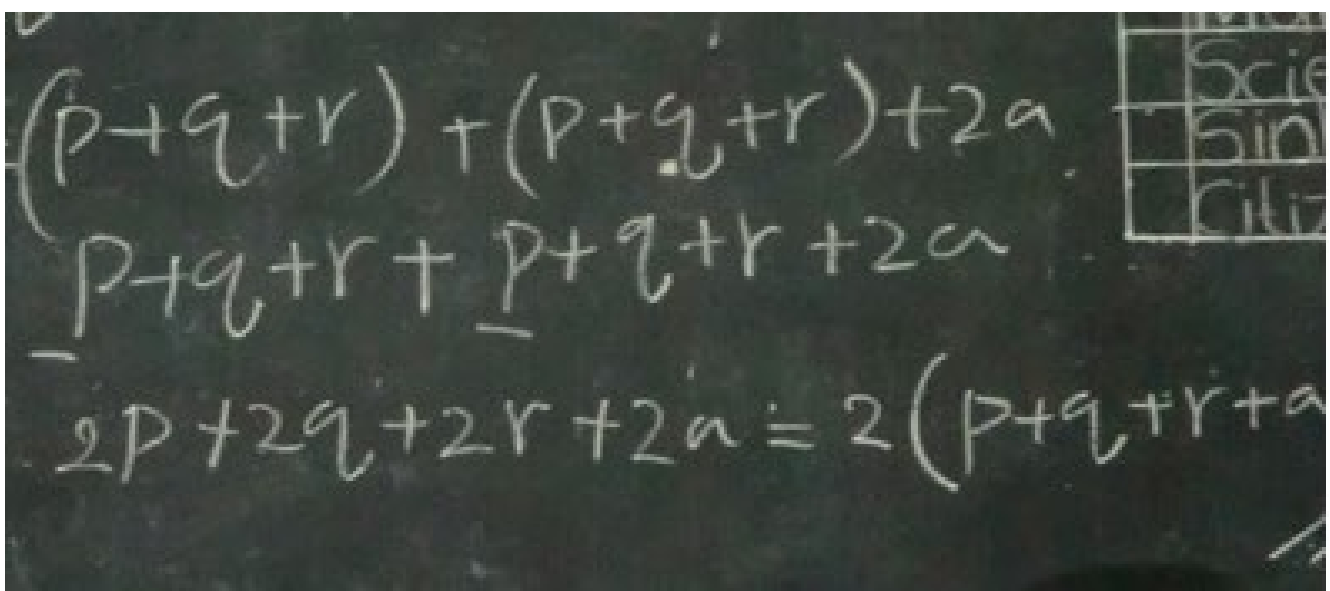

Figure 2. An illustration given in Jayani's lesson while constructing an algebraic expression.

Students: "Can't, ... can, can put two and brackets.”

Teacher: "Some of you have done...these two are two different factors. Removing brackets by multiplying... have written so. Are all these methods correct or not?"

Students: "Correct.”

By discussing with the whole class, the two approaches used by other students to solve the problem, the teacher encouraged the students to solve mathematics problems flexibly, without sticking to a fixed method.

A classroom incident that reflects the sensitizing concept Fixed steps in solving problems is described below to make it sensible for the reader as an example.

\subsubsection{Incident from Sudam's lesson (Fixed steps in solving problems):}

Context: This incident involves a situation in which the students did not use the required method their teacher expected them to use when simplifying an algebraic expression. The task had three parts. First, students were required to construct an algebraic expression to represent a given scenario, which they did, creating the 
equation: $4 a+16 b+40$. Second, they were to rewrite it as an algebraic expression with brackets, which led to the equation: $2(2 a+8 b+20)$. Third, they were asked to calculate the value of the algebraic expression, given that $a=5$ and $b=2$.

The teacher expected the students to substitute the values for $a$ and $b$ into the bracketed expression, $2(2 a+8 b+20)$. However, the students instead substituted $a=5$ and $b=2$ into the original equation, $4 a+16 b+40$. One student came to the blackboard and wrote down the following steps (Figure 3):

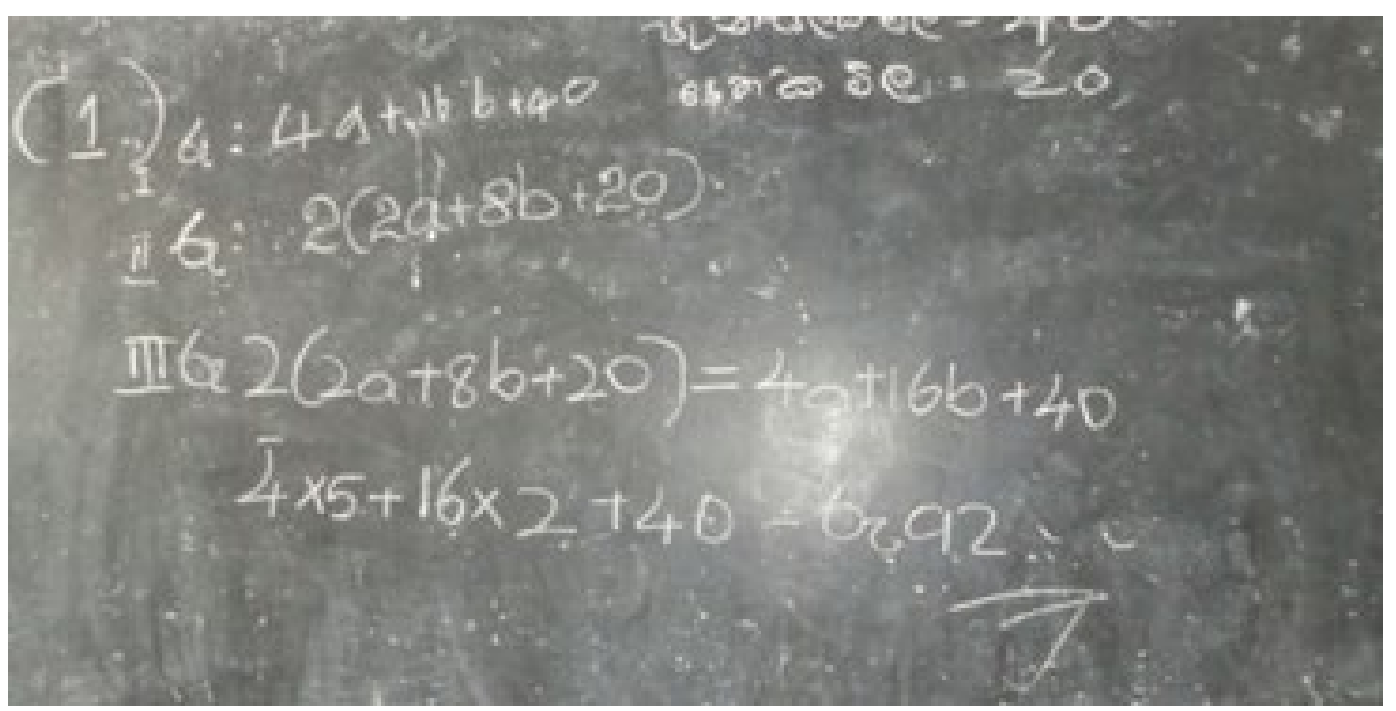

Figure 3. A student's calculation of the value of an algebraic expression by substituting the given values.

Teacher: "You were supposed to substitute to this. [Pointing to $2(2 a+8 b+20)$.] I think none of you have done so." [The teacher showed the whole class how to do it, again.]

$$
2(2 a+8 b+20)
$$

$$
2(2 \times 5+8 \times 2+20)
$$

Teacher: "Look here, how much...when simplifying the things inside the bracket.”

$$
2(10+16+20)
$$

Students: "Forty-four, forty-six." 
Teacher: "Forty-six multiply by two gives how much? Ninety-two. This is the process you were told to follow. Nobody did so. I didn't say you were to remove the brackets and simplify. [a bit rougher voice than his usual tone.] This is the way to simplify when it contains a bracket. If you have not written it down, write it now.”

\subsubsection{Characteristics of instructional practices of Sudam and Jayani}

The frequency of occurrences in each sensitizing concept (see Table 4) show the salient features of the teaching and learning approaches adopted by the two prospective teachers, with respect to the rigid view and flexible view aspects. An analysis of classroom teaching practices yielded evidence of both rigid and flexible practices, but none that was either highly rigid or highly flexible. For example, the two participants commonly posed questions to enable students to express their ideas or understandings, but activities such as exploration tasks, which encourage students to construct knowledge on their own, were rare.

Sudam adopted both slightly rigid and slightly flexible practices. In his practices, he attempted to build students' mathematical understanding of the content by providing principle-oriented explanations as a first step and having them systematically practice mathematics exercises. He seemed more likely to focus on mathematical understanding than on doing mathematics by drilling and practicing. Although there were Rigid View incidents, they basically happened to help students learn to solve mathematics problems systematically and to proceed more easily by keeping up their memory of technical terms, etc. He also showed concern about keeping slight variations (see Table 5) when selecting in-class exercises to practice, rather than repeatedly practicing similar problems. Altogether, these activities showed that his practices were somewhat more flexible than they might appear.

Jayani adopted mainly flexible practices and was very unlikely to implement Rigid View practices (see Table 4). She mentioned that knowing different methods to solve the same problem gives students opportunities to think about more efficient methods. She often focused on helping students gain mathematical understanding. Neither teacher employed purely inquiry-based learning activities; instead, they led discussions to encourage students to learn the content in a meaningful manner. 


\subsubsection{Evidence from the Post-Lesson Interviews of Sudam and Jayani}

The instructional practice features observed can be further explained by the evidence gathered in post-lesson interviews. Based on the case study teachers' explanations, several other factors were identified as mediating variables that impacted on practices and are noted in Table 5 .

\subsubsection{Instances from the post-lesson interviews}

Table 5. Explanations given by the cases to describe the particular features of their practices.

\begin{tabular}{|c|c|c|}
\hline Feature & Explanations quoted from post-lesson interviews & $\begin{array}{l}\text { Mediating } \\
\text { variable }\end{array}$ \\
\hline S1 & $\begin{array}{l}\text { Sudam: "Generally speaking, because a lesson like algebraic expressions } \\
\text { seems more abstract in nature, such abstract matters should be explained } \\
\text {.... because Grade Seven and Eight pupils... like relating to concrete } \\
\text { materials. If it is done in a more practically-oriented manner, even better." }\end{array}$ & $\begin{array}{l}\text { Psychological } \\
\text { aspects of } \\
\text { learning }\end{array}$ \\
\hline S2 & $\begin{array}{l}\text { Interviewer: "Can you elaborate, what do you mean by practically } \\
\text { oriented?" } \\
\text { Sudam: "It would have been better if it was done with objects, but, see, the } \\
\text { timing problem is there. See... in a lesson like on algebraic expressions, to } \\
\text { introduce terms such as unknowns... for example, putting some pencils or } \\
\text { such kind of objects in a box, so that pupils do not know exactly how many } \\
\text { objects there are inside,... therefore, pupils would say x, they would say y,... } \\
\text { such unknown terms would be expressed. Like that... It would have been } \\
\text { better if it had done so, but the thing is, there is not sufficient time." }\end{array}$ & $\begin{array}{l}\text { Time } \\
\text { constraints }\end{array}$ \\
\hline S3 & $\begin{array}{l}\text { After constructing algebraic expressions teacher gave students following } \\
\text { exercises to simplify; } \\
2 x+5 x+3 x \\
5 a b+a b+2 a b \\
2 p+2 q+3 q-p \\
\text { His explanation for selecting the exercises: } \\
\text { Sudam: "It's about moving from simplicity to complexity. Now... first, } \\
\text { understanding the like terms, next one is like terms too... but a bit more } \\
\text { complex. See... the type of unknown is presented as multiplication of two } \\
\text { unknowns. The next presents mixing like terms and unlike terms." }\end{array}$ & $\begin{array}{l}\text { Simplicity to } \\
\text { complexity }\end{array}$ \\
\hline \multirow[t]{2}{*}{ J2 } & $\begin{array}{l}\text { Jayani: "When I was a student in school, a teacher of mine often had... no } \\
\text { time to observe all our work when there were many... who comes first to } \\
\text { show their books are correct and then ... problematic situations were } \\
\text { discussed. Perhaps we might have made the same mistake, then at the } \\
\text { same time we can correct it. That is that." }\end{array}$ & $\begin{array}{l}\text { Previous } \\
\text { experiences as a } \\
\text { student }\end{array}$ \\
\hline & $\begin{array}{l}\text { Interviewer: "Other reasons if any?" } \\
\text { Jayani: "Yes, another thing is that the answer may be correct, but the }\end{array}$ & Exam \\
\hline
\end{tabular}


Similarities and differences in the case study teachers' practices on two perspectives (beliefs and mediating variables) are elaborated below.

\subsubsection{Comparison of practices based on professed beliefs}

The incidents related to Flexible View and Rigid View (see Table 4) show that both participants were likely to emphasize certain characteristics of flexible practices, such as promoting principle-oriented explanations. However, other characteristics such as alternative methods of solving problems and exploration activities were rare.

\subsubsection{Beliefs and practices of Sudam:}

Most of the Rigid View incidents in his practices were related to providing procedure-oriented explanations and emphasizing the memorization of factual knowledge. Moreover, in Sudam's practices, the frequencies of the Flexible View and Rigid View incidents were similar. However, as previously noted, his practices were mostly flexible as described in 5.2.2.3.

The results suggest that Sudam was likely to maintain both rigid and flexible practices, but his overall practices were more flexible in that they placed more emphasis on meaningful learning. His professed beliefs seemed more flexible view oriented, and his practices reflected his professed beliefs to a certain extent.

\subsubsection{Beliefs and practices of Jayani:}

In Jayani's practices, she attempted to make her pupils aware of the different solution approaches used by their peers, indicating her enthusiasm for flexible view teaching approach. She also wanted students to think of other ways of solving a given problem, rather than fixing on just one method. Moreover, Jayani's lessons featured substantially more Flexible View incidents than Rigid View incidents, suggesting she was more likely to maintain flexible practices than rigid practices.

The results suggest that Jayani's professed beliefs were more Flexible View oriented, as shown in her classroom teaching. 
In sum, no exploration tasks were found in either prospective teacher's practices, but both often attempted to provide necessary mathematical arguments or facts to make pupils more aware of what they were doing, how certain procedural steps worked, and so forth. Both teachers also attempted to enhance students' mathematical understanding by adopting different representational strategies and by helping students overcome their difficulties through strengthening their conceptions. The above evidence shows that both case study participants exhibited certain flexible practice behaviors in their classroom teaching, although one also exhibited certain rigid practice behaviors. In other words, Flexible View -supported behaviors were common to both, while Rigid View -supported behaviors were not. Moreover, as revealed by the belief's questionnaire, both case study participants' professed beliefs about the nature of mathematics and of teaching and learning mathematics were more flexible view oriented. Therefore, it appears that their actual classroom instructional practices were shaped, to a certain extent, by their professed beliefs.

\subsubsection{Impact of mediating variables on practices}

Explanations given by the participants during post-lesson interviews provide further evidence that extend understanding of their instructional practices (Table 5). Both case study participants attempted to create a teaching/learning environment that was, to a certain extent, supported by flexible practices, due to the teaching and learning theories (psychological aspects of learning mathematics) they had learnt in their teacher education course which emphasized the need to create meaningful learning situations in their instructional practices. These facts are consistent with their professed beliefs. However, contextual factors such as time constraints, expectations of an examination-oriented culture and previous learning experiences as a student have also influenced their practices. In other words, their professed beliefs about the nature of mathematics and of teaching and learning mathematics encouraged them to adopt flexible practices, albeit to differing extents due to the influence of other factors. 


\section{Discussion and Conclusion}

The overall analysis above indicates that the two case study teachers' professed beliefs had influenced their practices. Both participants held Flexible Views and the practices of both comprised more Flexible View than Rigid View aspects. The results also revealed that contextual factors such as examination-oriented expectations, time constraints and previous learning experiences of the teacher also caused differences in their actual practices.

To summarize, the study found that the participants' professed beliefs (flexible views on teaching and learning mathematics) affected their practices to varying extents but were restricted by the underlying social and contextual characteristics of the research site. Such consistencies between beliefs and practices were reported in prior studies in the area (Stipek et al., 2001; Temiz \& Topcu, 2013) as well as the inconsistencies (Cooney, 1985, Raymond 1997). The study contributes to the extant literature (Thompson, 1992, Goldin et al., 2016) by adding evidence from the Sri Lankan context on the role of beliefs in mathematics teaching.

\section{References}

An, S., Kulm, G., \& Wu, Z. (2004). The pedagogical content knowledge of middle school mathematics teachers in China and the U.S. Journal of Mathematics Teacher Education, $7(2), 145-172$.

An, S., Kulm, G., Wu, Z., Ma, F., \& Wang, L. (2006). The impact on cultural differences on middle school mathematics teachers' beliefs in the U.S. and China. In Leung, F. K. S., Graf, K. D., \& Lopez-Real, F. J. (Eds.), Mathematics education in different cultural traditions (Vol. 9) (pp 449-464). New York, NY: Springer.

Cooney, T. J. (1985). A beginning teacher's view of problem solving. Journal for Research in Mathematics Education 16(5), 324-336.

Ernest, P. (1989). The impact of beliefs on the teaching of mathematics. In P. Ernest (Ed.), Mathematics teaching: The state of the art. London, England: Falmer Press.

Ernest, P. (1991). The Philosophy of Mathematics Education. London, England: Falmer Press.

Furinghetti, F., \& Pehkonen, E. (2002). Rethinking characterizations of beliefs In G. C. Leder, Pehkonen, E. \& Toner, G. (Ed.), Beliefs: A hidden variable in mathematics education? (pp. 39-57). Dordrecht, The Netherlands: Kluwer.

Goldin, G., Hannula, M., Heyd, E., Jansen, A., Kaasila, R., Lutovac, S., Di Martino, P., Morselli, F., Middeleton, J., Pantziara, M., \& Zhang, Q. (2016). Attitudes, beliefs, motivation and identity in mathematics education: An overview of the field and future directions. ICME13 Topical Surveys. Switzerland: Springer.

Hart, L. C. (2002). Preservice teachers' beliefs and practice after participating in an integrated content/methods course. School Science and Mathematics, 102(1), 4-14. 
Leder, G. C., Pehkonen, E., \& Toner, G. (2002). Setting the scene. In G. C. Leder, E. Pehkonen \& G. Toner (Eds.), Beliefs: A hidden variable in mathematics education? Dordrecht, The Netherlands: Kluwer.

Leung, F. K. S. (1995). The Mathematics classroom in Bejing, Hong Kong and London. Educational Studies in Mathematics, 29(4), 297-325.

Leung, F. K. S., Graf, K. D., \& Lopez-Real, F. J. (Eds.). (2006). Mathematics education in different cultural traditions: A comparative study of East Asia and the West (Vol. 9). New York, NY: Springer.

McLeod, D. (1992). Research on affect in mathematics education: A reconceptualization. In D.

A. Grouws (Ed.), Handbook of research on mathematics teaching and learning (pp. 575-596). New York, NY: Macmillan.

Pajares, M. F. (1992). Teachers' beliefs and educational research: Cleaning up a messy construct. Review of Educational Research, 62(3), 307-332.

Pepin, B., \& Roesken-Winter, B. (Eds.). (2015). From beliefs to dynamic affect systems in mathematics education. Cham, Switzerland: Springer.

Raymond, A. M. (1997). Inconsistency between a beginning elementary school teacher's mathematics beliefs and teaching practice. Journal for research in mathematics education 25(5), 550-576.

Seah, W. T., Andersson, A., Bishop, A., \& Clarkson, P. (2016). What would the mathematics curriculum look like if values were the focus? For the learning of mathematics, 36(1), 1420.

Stipek, D. J., Givvin, K. B., Salmon, J. M., \& MacGyvers, V. L. (2001). Teachers' beliefs and practices related to mathematics instruction. Teaching and teacher education, 17(2), 213226.

Swars, S., Hart, L. C., Smith, S. Z., Smith, M. E., \& Tollar, T. (2007). A longitudinal study of elementary pre-service teachers' mathematics beliefs and content knowledge. School Science and Mathematics, 107(8), 325-335.

Tatto, M. T., Schwille, J., Senk, S., Ingvarson, L., Peck, R., \& Rowley, G. (2008). Teacher Education and Development Study in Mathematics (TEDS-M): Conceptual framework. East Lansing,. MI: Teacher Education and Development International Study Centre, College of Education, Michigan State University.

Temiz, T. \& Topcu, M. S., (2013). Preservice teachers' teacher efficacy beliefs and constructivistbased teaching practice. European journal of psychology of education 28(4), 1435-1452.

Thompson, A. G. (1992). Teachers' beliefs and conceptions: A synthesis of the research. In D. A. Grouws (Ed.), Handbook of research on mathematics teaching and learning (pp. 127-146). New York: Macmillan.

Van Zoest, L. R., Jones, G. A., \& Thornton, C. A. (1994). Beliefs about mathematics teaching held by pre-service teachers involved in a first-grade mentorship program. Mathematics Education Research Journal, 6(1), 37-55.

Wadanambi, G. M. \& Leung, F. K. S. (2016). Sri Lanka's pre-service teachers' professed beliefs about nature of mathematics and learning and teaching mathematics. Paper presented at the $13^{\text {th }}$ International Congress on Mathematics Education (ICME 13). The University of Hamburg, Germany. 